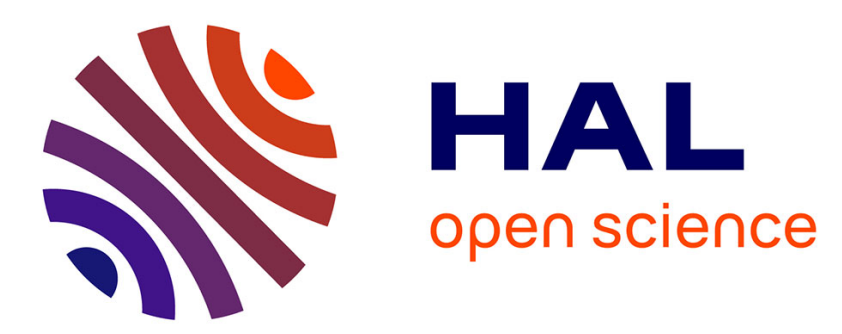

\title{
Large Eddy Simulation for flows through emerged or slightly sub-merged square obstacles
}

Marina Oukacine, Rajae Rtimi, Nicole Goutal, Frédérique Larrarte, Vincent Loizeau, Sofiane Benhamadouche, Sébastien Proust

\section{To cite this version:}

Marina Oukacine, Rajae Rtimi, Nicole Goutal, Frédérique Larrarte, Vincent Loizeau, et al.. Large Eddy Simulation for flows through emerged or slightly sub-merged square obstacles. River Flow 2020 -10th Conference on Fluvial Hydraulics, Jul 2020, DELFT, France. 8 p. hal-02933751

\section{HAL Id: hal-02933751 \\ https://hal.science/hal-02933751}

Submitted on 8 Sep 2020

HAL is a multi-disciplinary open access archive for the deposit and dissemination of scientific research documents, whether they are published or not. The documents may come from teaching and research institutions in France or abroad, or from public or private research centers.
L'archive ouverte pluridisciplinaire HAL, est destinée au dépôt et à la diffusion de documents scientifiques de niveau recherche, publiés ou non, émanant des établissements d'enseignement et de recherche français ou étrangers, des laboratoires publics ou privés. 


\title{
Large Eddy Simulation for flows through emerged or slightly sub- merged square obstacles
}

\author{
M. Oukacine, R. Rtimi, N. Goutal \& F. Larrarte \\ Laboratoire Hydraulique Saint-Venant, Chatou, France
}

R. Rtimi, N. Goutal, V. Loizeau \& S. Benhamadouche

EDF R\&D, Chatou, France

S. Proust

Riverly Research Unit, INRAE, Villeurbanne, France

F. Larrarte

Univ. Gustave Eiffel, Marne la Vallée, France

\begin{abstract}
As a result of climate change, we believe that extreme floods will become more frequent and more intense. The flows through obstacles representing an urbanized floodplain is realised in a laboratory at $\mathrm{Re}=4766$ and 8580 . The purpose of the present study is first to validate a numerical model using Large Eddy Simulation (LES) against experimental data regarding the average longitudinal velocity and the secondary vortices formation. Then, additional data can be obtained and quantified. Therefore the geometrical parameters can be changed and their influence analysed and compared to the literature. A good agreement was found between simulated and experimental vertical profiles of time averaged velocity for the flow through emerged or slightly submerged obstacles. The additional simulations highlight that the flow structure is mostly driven by the transverse aspect ratio using the distance between two adjacent obstacles.
\end{abstract}

\section{INTRODUCTION}

As a result of climate change, we believe that extreme floods will become more frequent and more intense. People and properties, such as housing and industrial facilities, must therefore be protected against these floods for which data are very scarce or even non-existent (European Union 2007). When moving from low to extreme flooding, the flood extent over the floodplain greatly varies. The nature of the obstacles encountered during the floods may change in the sense that they can be emerged for moderate flows or slightly submerged for high flows. Thanks to an experimental set-up, the uniform flow structure around a square array of emerged or slightly submerged square cylinders has been investigated and the measurements focused particularly on the vertical profile of the mean longitudinal velocity. The behaviour of the vertical profiles depends on the lateral and vertical confinements. The objectives of the present works are twofold; first we aim at validating a 3D numerical modelling in order to create a "numerical channel" able to reproduce the flow through the obstacles, second as a result of this validation, we numerically explore the influence of the geometrical parameters such as the lateral confinement on the flow structure.

\section{EXPERIMENTAL SET-UP}

\subsection{Validation test-case description}

The experiments were performed at the Hydraulic and Hydromorphologic laboratory at INRAE Lyon-Villeurbanne, France. The experiments were carried out in a $1 \mathrm{~m}$ wide and $17.25 \mathrm{~m}$ long open-channel flume with a rectangular cross-section (Fig. 1a). The bed slope $\mathrm{S}_{0}$ was equal to 1.05 $\mathrm{mm} / \mathrm{m}$, and the glass flume bottom was covered with dense artificial grass $(0.005 \mathrm{~m}$ high rigid blades, see Fig. 1b). The water level is controlled by an adjustable vertical downstream weir. The vertical axis $\mathrm{Oz}$ is aligned with the vertical direction (normal to the flume bottom), its origin $\mathrm{z}_{0}$ is 
defined at the top of the rigid blades. The left-hand side wall, made of glass, is located at $\mathrm{z}=0$, and the right-hand side wall, made of Plexiglas, is at $y=1 \mathrm{~m}$. Over the artificial grass, 833 ( $7 \times 119)$ square cylinders were placed in a square array pattern (Fig. 1c). Each square cylinder has a square cross-section with a $0.064 \mathrm{~m}$ side length and a $0.0592 \mathrm{~m}$ height. The square cylinder height $\mathrm{k}$ is measured from the top of the grass blades (Fig. 1b).The distance 1 between two adjacent square cylinders is identical in the transverse and longitudinal directions and equals to $0.079 \mathrm{~m}$. The distance between the side wall and the nearest square cylinder is $0.039 \mathrm{~m}$. The first transverse row of square cylinders starts at $0.17 \mathrm{~m}$ downstream of the channel entrance $(\mathrm{x}=0)$. Each transverse row is composed of 7 square cylinders, with 119 transverse rows along the channel (49 square cylinders $/ \mathrm{m}^{2}$ ). Two immersion rates $\mathrm{H} / \mathrm{k}$ equal to $93 \%$ and $148 \%$, respectively, are studied, $\mathrm{H}$ being the flow depth (Oukacine 2019). Time averaged velocities and velocity fluctuations were measured using an Acoustic Doppler Velocimetry (ADV) with a side looking probe, a Particle Image Velocimetry (PIV) system (2D-2C) and a Large Scale Particle Image Velocimetry (LSPIV). The uncertainty of ADV measurement is $0.5 \%$ of the value measured $\pm 1 \mathrm{~mm} . \mathrm{s}^{-1}$ (manufacturer's data).

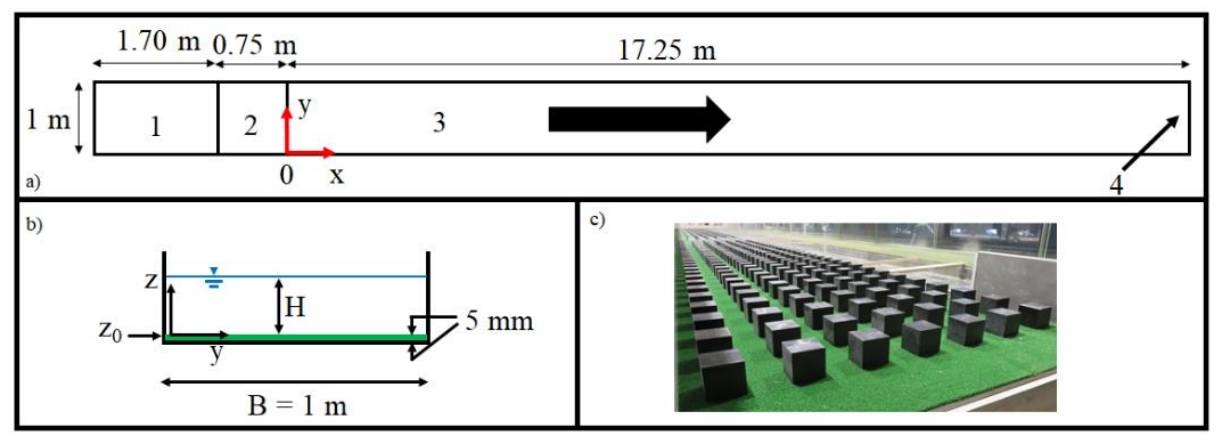

Figure 1. a) Schematic top view of the open-channel: inlet tank (1), vertical linear ramp with a $15 \%$ slope (2), working channel length (3), downstream weir (4), b) Sketch of the cross section: B = channel width, $\mathrm{H}=$ flow depth, $\mathrm{z}_{0}$ located at the top of the artificial grass blades, c) Picture from downstream of the square cylinders

\subsection{Main results}

The obstruction created by the obstacles results in wake zones behind the houses models (square cylinders), while a high-speed stream is located between two square cylinders. Flow is mainly one-dimensional in the longitudinal direction in the high speed-stream. The presence of obstacles implies that the characteristic velocity of the flow is not the bulk velocity $\mathrm{u}_{\mathrm{Q}}$ but the porosity velocity $u_{\Phi}$ which takes into account the obstruction of the obstacles (Oukacine 2019). For flows through emergent obstacles, the vertical profile of time-averaged streamwise velocity is characterised by a dip phenomenon (Nezu \& Nakagawa 1984), i.e. a deceleration of the flow in the nearsurface layer due to helical secondary currents. This flow configuration can therefore be considered as a succession of flows on narrow channels, whose characteristic width is therefore the distance between square cylinders 1 thus the lateral aspect ratio $\mathrm{Ar}_{\mathrm{y}}=1 / \mathrm{H}$ instead of $\mathrm{B} / \mathrm{H}$. The dip phenomenon, generated by secondary currents, is thus caused by the lateral confinement. In addition, the turbulent intensity is greater than $30 \%$ with the presence of vortex shedding located at the vertical square cylinder edges. In the case of emergent square cylinders $(\mathrm{H} \leq \mathrm{k})$, the results show that flow depth does not influence the flow structure (mean flow and turbulence statistics). For slightly submerged cylinders, flow structure is unchanged below the top of the square cylinders. Around $\mathrm{z}=\mathrm{k}$, there is a mixing zone and above the fluid accelerates with a velocity distribution following a log-law, typical of wide channels. Last, a strong decrease in the turbulence intensity is observed from emergence to submergence conditions of the square cylinders. 


\section{NUMERICAL SIMULATIONS}

A 3D modelling of the experimental channel is performed using an open-source software which solved the Navier-Stokes equations Code_Saturne (www.code-saturne.org, Archambeau 2004). It is developed and distributed by EDF to solve fluid dynamics problems (CFD). It uses a collocated finite volume technique for computational cells of any shape. Pressure/velocity coupling is ensured via a SIMPLEC algorithm. Several turbulence models are available: from Reynolds Average Navier-Stokes models (RANS, eddy viscosity and Reynolds Stress models) to Large Eddy Simulation models (LES, Standard and dynamic Smagorinsky, Wale).

\subsection{Modelling hypothesis}

Three modeling hypotheses are made. The two first hypotheses would not a priori affect the predominant physical phenomenon (Oukacine 2019). The third one is more important but as our interest is on the vertical flow profile, it should not affect the targeted physics that much.

The first one is the non-accounting of the channel slope $S_{0}$ as it is incompatible with the biperiodic boundary condition (periodic boundary conditions will be explained in the next paragraph). The flow will not be imposed by the slope but thanks to a pressure gradient.

The second one is that the bottom roughness is not taken into account. In fact, the predominant physical phenomenon generating turbulence is not the roughness but the obstacles in the flow evaluated with the 1D momentum equation (Oukacine 2019). The ratio between bottom roughness over the drag is equal to $+7.5 \%$ for the $93 \%$ flow and $+9.4 \%$ for the $148 \%$ flow. Here, the modelled channel will be a smooth-bottomed channel with no slip boundary conditions $(\bar{u}, \bar{v}, \bar{w}=0)$.

The third hypothesis is more significant: the free surface is not taken into account and a flat free surface is imposed. This will influence some physical phenomena, such as the interaction of surface vortex detachments with the free surface. Here, the goal is to highlight the vertical profile of the flow. The obtained results will determine whether the fixed surface influences the vertical profile of the flow or not. A symmetry plane is imposed; if, $(\mathrm{u}, \mathrm{v}, \mathrm{w})$ stand for the velocity components, one has $\partial \bar{u} / \partial z=\partial \bar{v} / \partial z$ and $\bar{w}=0$.

\subsection{Initial and boundary conditions}

The pattern used is made of two rows of two cylindrical arrays (Fig. 2). Periodic boundary conditions are applied in the longitudinal and transverse directions, respectively. The established regime found in the experiment justifies the condition of longitudinal periodicity (the number of rows seems to be enough to obtain a fully developed flow regime after some rows).

In addition, the fixed free surface condition will prevent flow to have interactions with a real free surface (Ouro et al. 2020). This will mean that the seiching will not be present and that the vortex detachments interacting with the free surface will not exist (Chetibi et al. 2019).

\subsection{Turbulence modelling}

A Wall-Adapting Local Eddy-viscosity model (WALE, Nicoud \& Ducros, 1999) is used. The meshes are of hexahedric shape. The LES capabilities of Code_Saturne have been on various academic and industrial cases including decaying isotropic turbulence, channel flows, side-byside cylinders, tube bundles and gusts over a plate; (see Benhamadouche 2006, Benhamadouche et al. 2017, 2019) for example. The temporal discretization for the LES is second order CrankNicolson in time with linearized convection. The spatial discretization is a pure second order central difference scheme. By default, there are no external sweeps on the pressure-velocity coupling. The mesh used is a very refined near-wall mesh, with $\Delta y^{+}=1$. Then, the mesh is unrefined according to a geometric progression of reason equal 1.1 (Fig. 2). Thus, a uniform mesh size is obtained far from the walls with a value of $y+$ between 5 and 10 . These characteristics correspond to the recommended values for the LES simulations of (Piomelli \& Chasnov, 1996). 


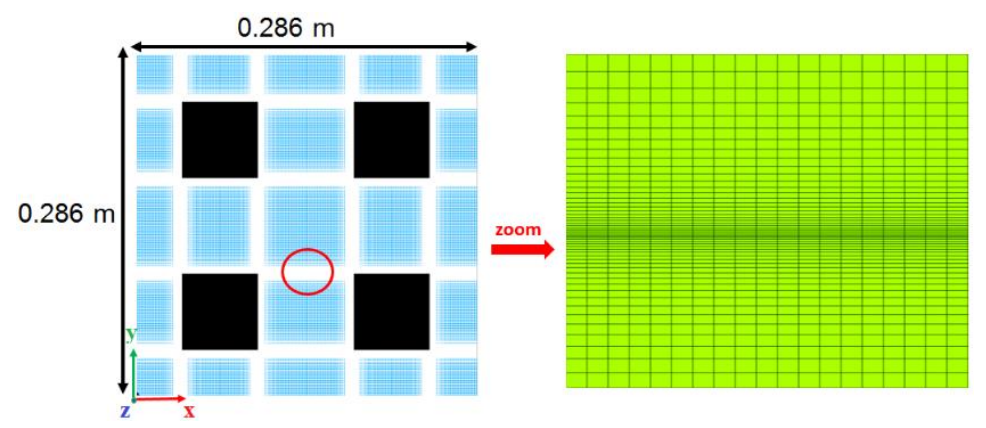

Figure 2. Computational domain and zoom of the mesh

\section{NUMERICAL RESULTS}

\subsection{Validation against experimental data}

The comparison of the simulations results with PIV and ADV experimental data validate the vertical profile of longitudinal velocity (Fig. 3). The parabolic shape of the mean longitudinal velocity $\bar{u}$, typical of narrow channels (Nezu \& Nakagawa 1984), is recovered. The simulation overestimates the maximum velocity position by $25 \%$. The overestimation is probably due to the friction at the bottom wall which is more important in the experiment. The major difference between the two velocity fields for the mean transversal velocity $\bar{v}$ is located behind the P3 square cylinder (Fig. 4), the one from the experiment is both positive and negative while it is mainly negative in the simulation. This is due to the fact that the roof is fixed and the detachments vortices are different between experiment and numerical simulation. Indeed, behind the square cylinders (Fig. 5), the experiment shows the formation of a single vortex while the numerical simulation generates two symmetrical vortices with respect to the center of the square cylinder. This configuration is typical of entrained cavity flows. Depending on the longitudinal location of the measurement, the shape of the velocity is related to the shape of the vortex (Fig. 5). Indeed, if one is located in the middle of the vein or closer to a square cylinder upstream or downstream, the shape of the vortex being different, the velocity is different (Fig. 5). The comparison of the vertical velocity $\bar{w}$ shows that at the center of the central vein the velocity is negative or nil (Fig. 4). However, the simulation underestimates the vertical velocity by $60 \%$.

Finally, the flow through emergent obstacles, despite the fixed free surface model, the mean longitudinal velocity is well approached. This reinforces the fact that the surface has little influence on the latter. However, these assumptions influence the vortices generations.

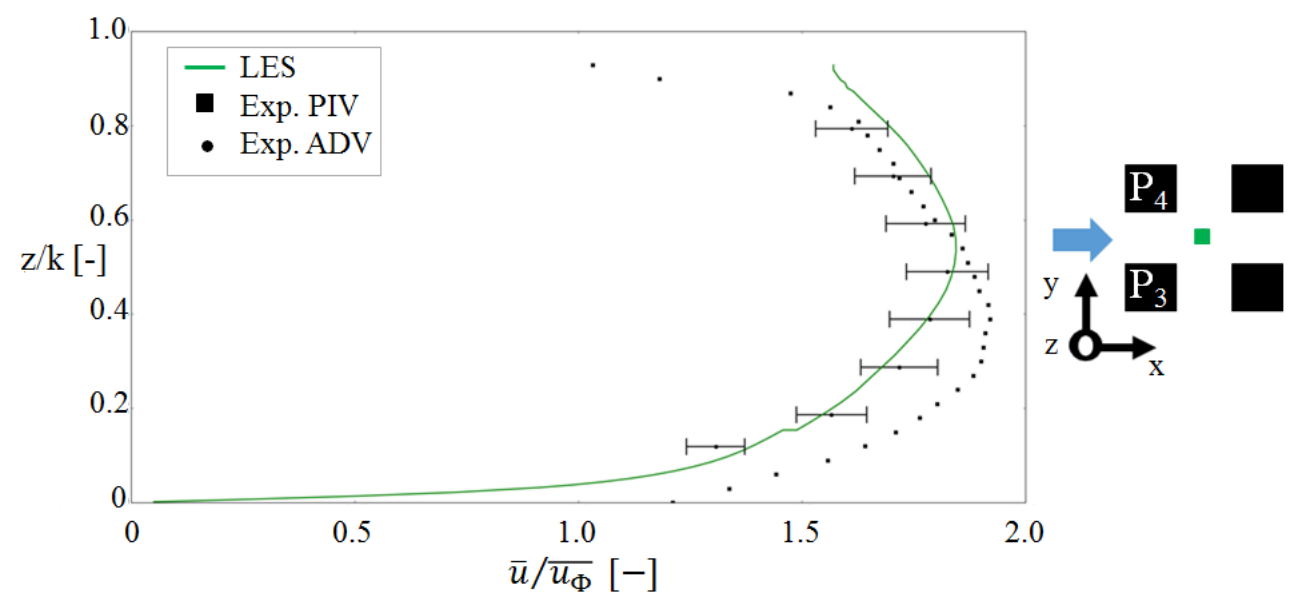

Figure 3. Comparisons for the flow through emerged obstacles $(\mathrm{H} / \mathrm{k}=93 \%)$ between PIV and ADV experimental measurements and LES simulations. Vertical mean longitudinal velocity $\bar{u}$ made non dimensional using the porosity velocity $\overline{u_{\Phi}}$. 

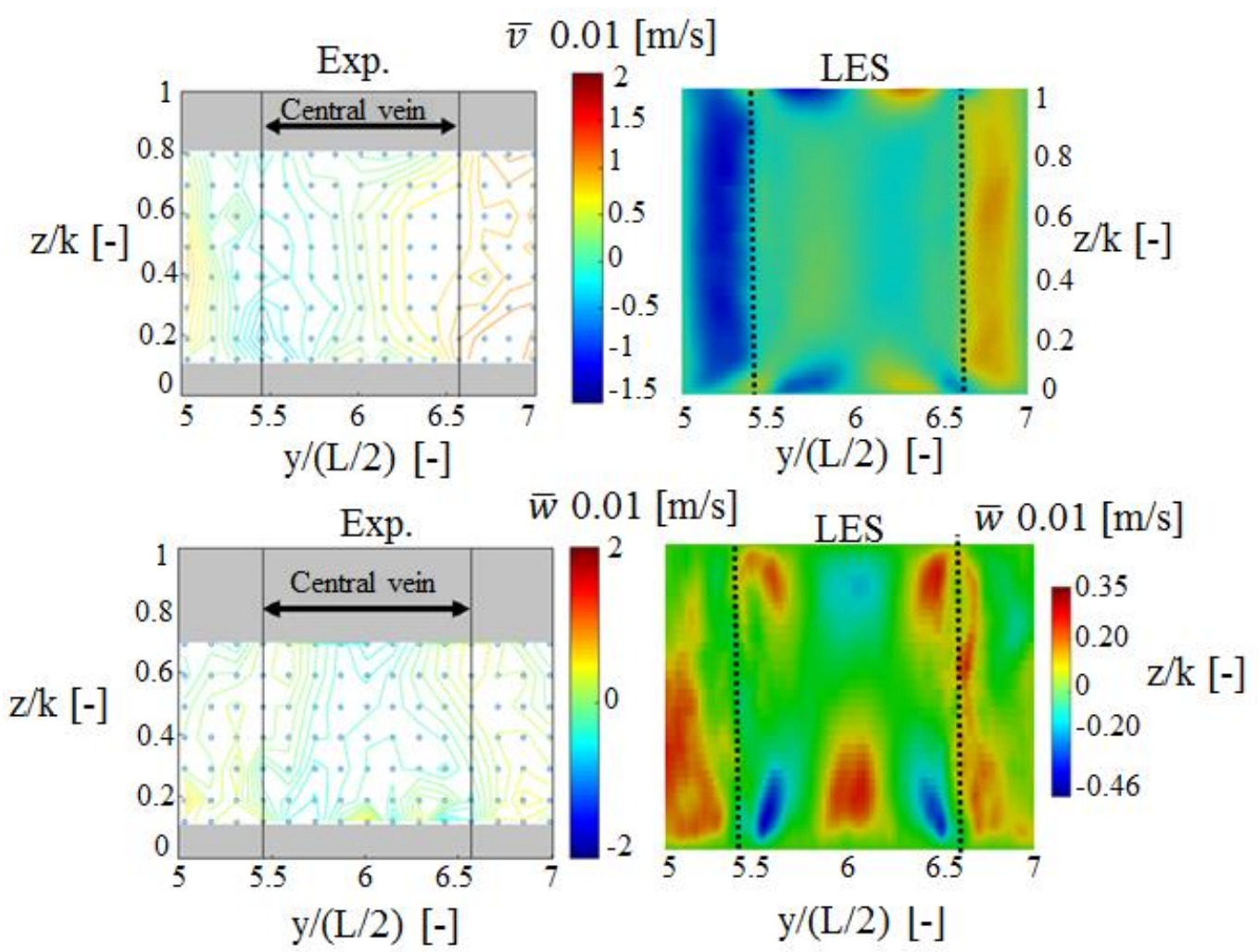

Figure 4. Comparisons for the flow through emerged obstacles flow $(\mathrm{H} / \mathrm{k}=93 \%)$ between ADV experimental measurements and LES simulations mean velocity components $\bar{v}, \bar{w}$ between the square cylinder 3 and 4 at $\mathrm{x}=0.143 \mathrm{~m}$ (Fig. 2)

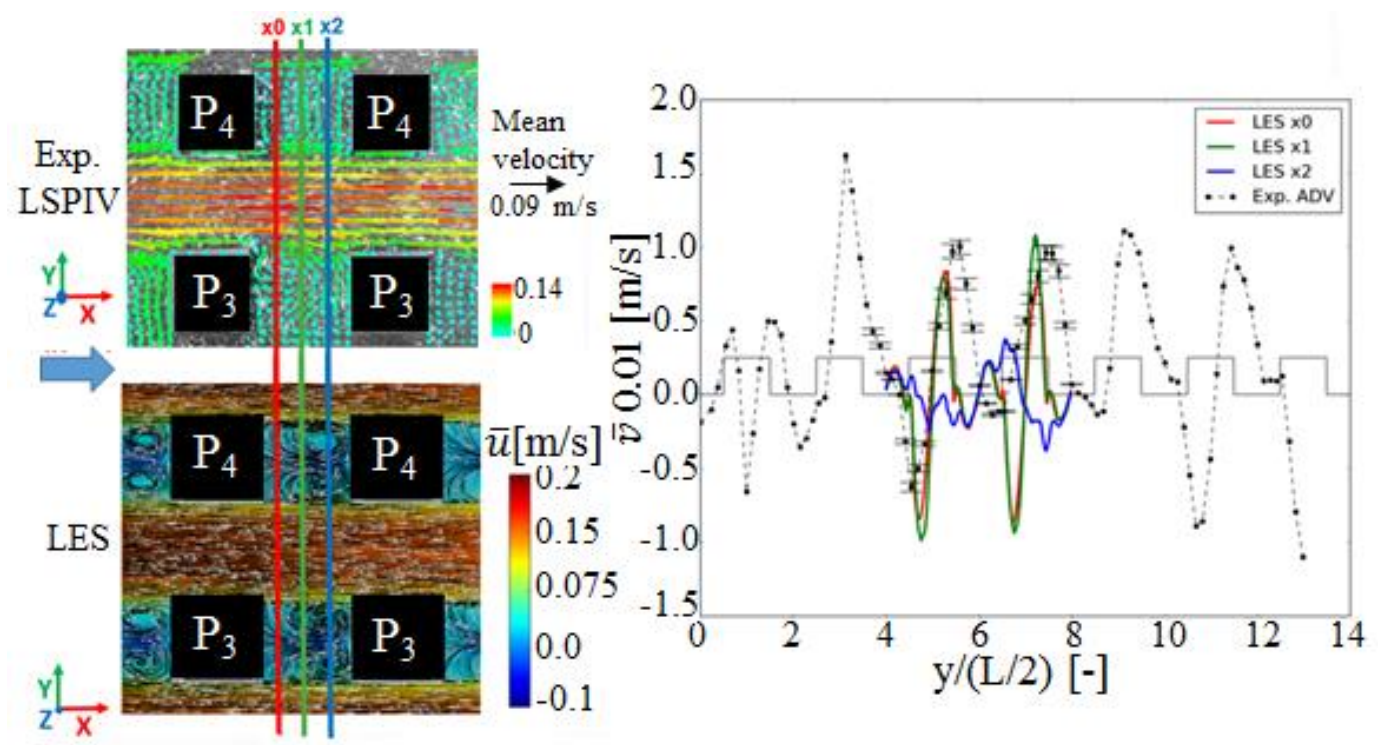

Figure 5. Comparison of the mean transverse velocity profiles $\bar{v}$ for the flow through emerged obstacles $(\mathrm{H} / \mathrm{k}=93 \%)$ at the position $\mathrm{z} / \mathrm{H}=44 \%$ between the ADV experimental data and the LES simulation for three longitudinal positions $\mathrm{x}_{0}, \mathrm{x}_{1}$ and $\mathrm{x}_{2}$ 
For the flow through submerged obstacles at $\mathrm{H} / \mathrm{k}=148 \%$, the maximum of the mean longitudinal velocity profile $\bar{u}$ is reached on the free surface for both experimental data and LES simulation (Fig. 6). At the elevation $\mathrm{z} / \mathrm{H}=44 \%$, the LES mean longitudinal velocity $\bar{u}$ is underestimated by $8 \%$.

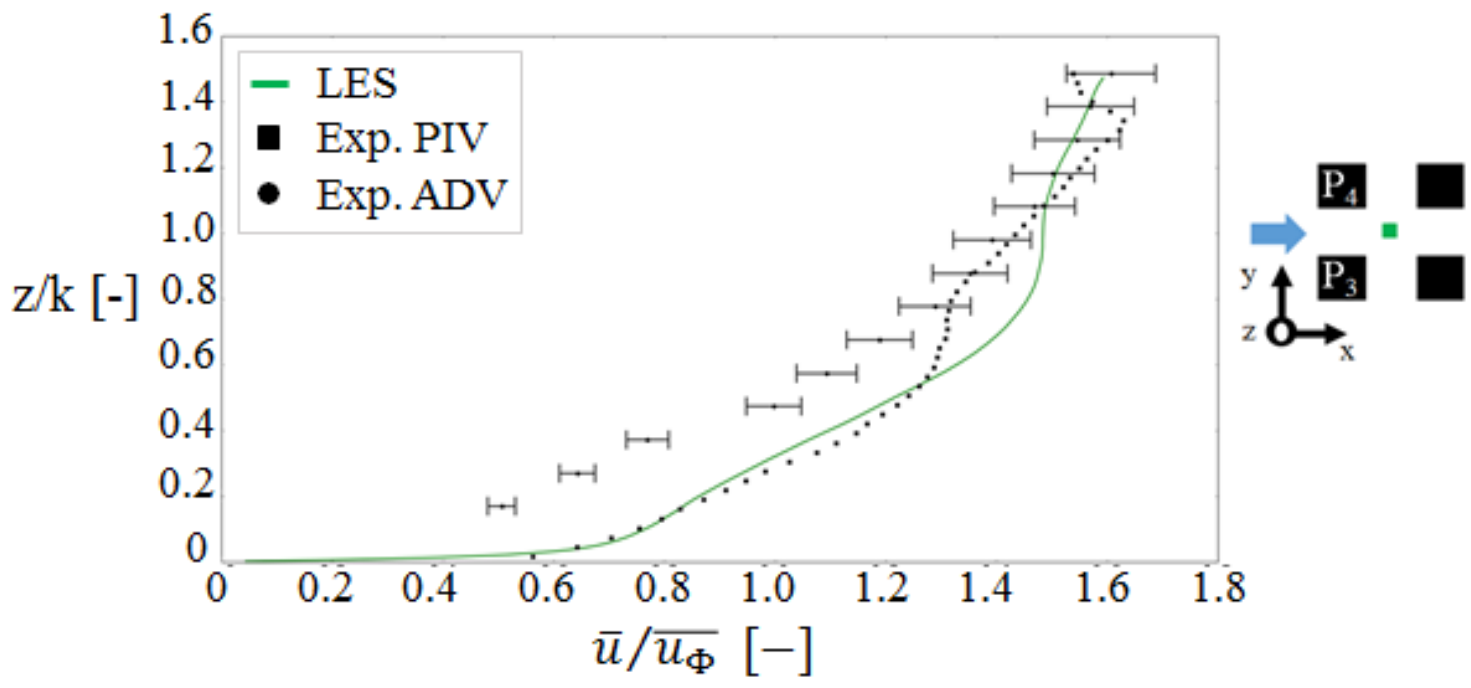

Figure 6 . The vertical mean longitudinal velocity $\bar{u}$ made non dimensional using the porosity velocity $\overline{u_{\Phi}}$ for the flow through submerged obstacles at $\mathrm{H} / \mathrm{k}=148 \%$. Comparisons between PIV and ADV experimental measurements and LES simulations at the green position between the square cylinder 3 and 4

The LES mean transverse velocity $\bar{v}$ is very close to the experiment (Fig. 7) with vortices at the position $\mathrm{z} / \mathrm{k}$ equal 0.6 and a negative velocity above the position $\mathrm{z} / \mathrm{k}$ equal 1 . This is due to the fact that the free surface is located above the roofs of square cylinders. On the other hand, at the position $\mathrm{z} / \mathrm{H}=42 \%$, the experiment and the LES are out of phase and the numerical simulation overestimates the amplitude of the velocity by $25 \%$ (Fig. 7).

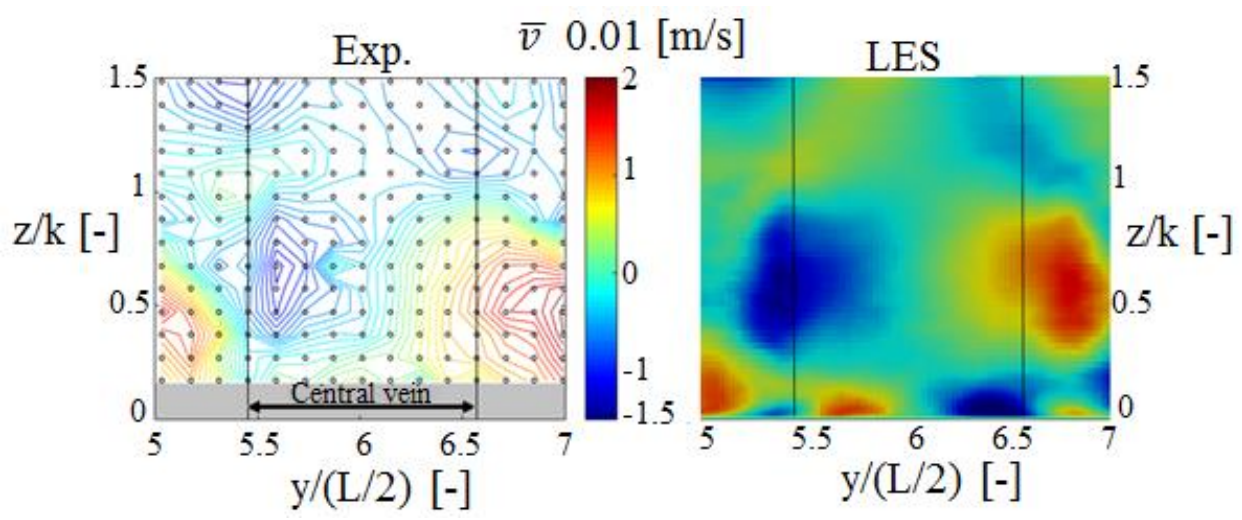

Figure 7. Comparisons for the flow through submerged obstacles flow $(\mathrm{H} / \mathrm{k}=148 \%)$ between ADV experimental measurements and LES simulations mean velocity components $\bar{v}$ between the square cylinder 3 and 4 at $\mathrm{x}=0.143 \mathrm{~m}$ (Fig. 2)

Regarding the mean vertical velocity $\bar{w}$, LES underestimated the area $\mathrm{z} / \mathrm{k}$ between 0.6 and 1.5 and overestimated by $50 \%$ the velocity at the edges (Fig. 8 ).

The results showed that for both flows, the vertical profile of the mean longitudinal velocity $\bar{u}$ is validated with the LES. 


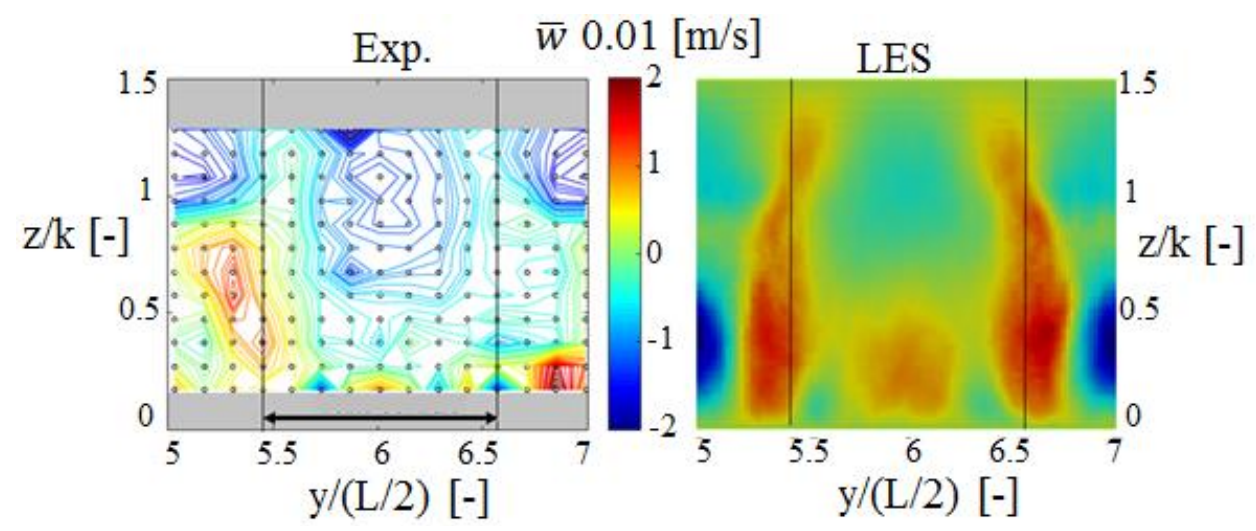

Figure 8. Comparisons for the flow through submerged obstacles flow $(\mathrm{H} / \mathrm{k}=148 \%)$ between ADV experimental measurements and LES simulations mean velocity components $\bar{w}$ between the square cylinder 3 and 4 at $\mathrm{x}=0.143 \mathrm{~m}$ (Fig. 2)

\subsection{Influence of the geometrical repartition of obstacles for the flow through emergent obstacles}

As LES has been fairly validated. It is now possible to explore others geometrical parameters that could not be experimentally conducted (Fig. 9). All the configurations below are numerical simulations using the same modelling assumptions as before with the same initial and boundaries conditions and the same mesh strategy and domain size. The obstacle density will be modified on the flow with emergent obstacles at 93\%. 17 configurations have been tested with different square cylinders sizes and always with the same water height i.e. $0.055 \mathrm{~m}$. Here, the inlet conditions remains unchanged. The flows were calculated using the formula of (Guillén-Ludeña et al., 2020). A quantitative approach to the velocity profile taken at the centre of the central vein is carried out. As a reminder, in the literature, it is the transverse aspect ratio $\mathrm{Ar}_{\mathrm{y}}$ that defines whether the channel is narrow -under 5- or wide -upper than 5- (Nezu \& Nakagawa 1984).

The objective is to assess whether the experimental value of $\mathrm{Ar}_{\mathrm{y}}$ is still valid for discontinuous channels and regardless of the longitudinal aspect ratio $\mathrm{Ar}_{\mathrm{x}}$. The number 0 represents the experimental configuration (Fig. 9).

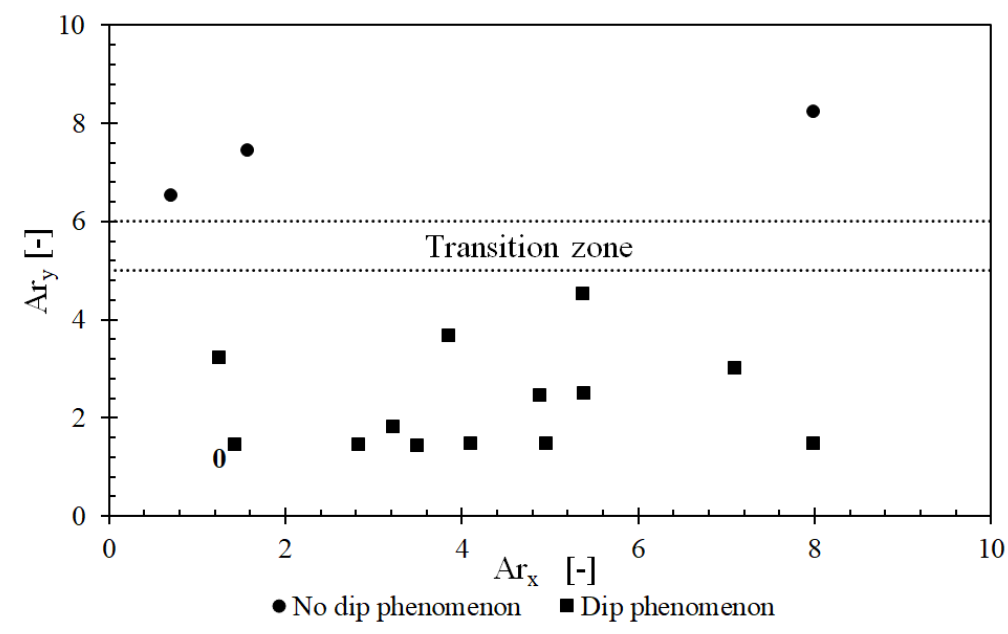

Figure 9. Classification of the configurations tested according to the aspect ratio $\operatorname{Ar}_{\mathrm{x}}$ and $\operatorname{Ar}_{\mathrm{y}}$ for different obstacles dimensions and spacing for the same flow depth $\mathrm{H}=0.055 \mathrm{~m}, 0$ is the experimental point

In the limited range of configurations studied, the results showed that when $\mathrm{Ar}_{\mathrm{y}}$ is under 6 regardless of longitudinal aspect ratio $\mathrm{Ar}_{\mathrm{x}}$, the dip phenomenon is still present. Here, in the case 
of discontinuous channel, it's still the transverse aspect ratio which governs the vertical profile of the mean longitudinal velocity.

\section{CONCLUSIONS}

Large Eddy Simulation based on solving Navier-Stokes equations with Code_Saturne, were carried out. First, they are validated from experimental measurements of vertical profiles of the mean longitudinal velocity $\bar{u}$ for both emergent and slightly submerged square cylinders uniform flow. The strong hypothesis of a fixed free surface has little influence on the vertical distribution of mean longitudinal velocity, even though it leads to differences in vortex formation and position. The representation of the interactions of the free surface with the vortex detachments would require LES simulations with consideration of the free surface. The validation of the vertical longitudinal velocity distributions made it possible to use a "numerical channel" to explore other geometric configurations that could not be experimentally performed and to observe their influence on the vertical profile of the mean longitudinal velocity.

The different configurations tested showed that, regardless of the longitudinal aspect ratio $\mathrm{Ar}_{\mathrm{x}}$, the cross-sectional aspect ratio $\mathrm{Ar}_{\mathrm{y}}$ plays a predominant role on the flow structure. So, the relationship found by (Nezu \& Nakagawa, 1984) remains valid even for discontinuous narrow channels. Work in progress would make it possible to study transitional situations.

\section{ACKNOWLEDGEMENT}

The authors acknowledge the support of the FlowRes project by the French National Research Agency (ANR), under grant NoANR-14-CE03-0010

\section{REFERENCES}

Archambeau, F., Mechitoua, F., \& Sakiz, N., 2004. "Code_Saturne: A finite volume method for the computation of turbulent incompressible flows: Industrial applications." International Journal on Finite Volumes. ISSN 1634 (0655) (2004). Electronical edition: http://averoes.math.univ-paris13.fr/html

Benhamadouche, S., 2006. Large-Eddy Simulation with the unstructured collocated arrangement. PhD thesis, The University of Manchester

Benhamadouche, S., Arenas, M., \& Malouf, W. 2017. "Wall-resolved Large Eddy Simulation of a flow through a square-edged orifice in a round pipe at $\mathrm{Re}=25,000$," Nuclear Engineering and Design, 312, pp. $128-136$

Benhamadouche, S., Afgan, I., Manceau, R., 2019. Numerical Simulations of Flow and Heat Transfer in a Wall-Bounded Pin Matrix. Flow turbulence and Combustion, Article in Press (2019).

Chetibi, M., Proust, S., \& Benmamar, S., 2019. Transverse surface waves in steady uniform and non-uniform flows through an array of emergent and slightly submerged square cylinders. Journal of Hydraulic Research, 1-13.

European Union. 2007. Directive 2007/60/ce du parlement européen et du conseil, du 23 octobre 2007, relative à l'évaluation et à la gestion des risques d'inondation. Journal officiel du l'union Européenne, 27-34.

Guillén-Ludeña, S., Lopez, D., Mignot, E., \& Riviere, N., 2020. Flow Resistance for a Varying Density of Obstacles on Smooth and Rough Beds. Journal of Hydraulic Engineering, 146(2), 04019059.

Nezu, I. \& Nakagawa, H. 1984. Cellular secondary currents in straight conduit. J. Hydr. Eng, 110(2):17319

Nicoud, F. \& Ducros, F. 1999. Subgrid-scale stress modelling base on the square of the velocity gradient tensor. Flow, Turbulence and Combustion 62(3):183-200.

Piomelli, U. \& Chasnov, J. 1996. Large-eddy simulations: theory and applications. Turbulence and transition modelling, Springer, 269-336.

Oukacine, M. 2019. Etude expérimentale et numérique des écoulements à surface libre en présence d'obstacles émergés à faiblement submergés, $\mathrm{PhD}$ thesis, Univeristé Paris Est (XI).

Ouro, P., Juez, C., \& Franca, M., 2020. Drivers for mass and momentum exchange between the main channel and river bank lateral cavities. Advances in Water Resources, 103511. 